\title{
3. Greifswalder Ryck-Symposium für MTRA
}

Warum nicht mal das Nützliche mit dem Angenehmen verbinden? - Gelegenheit dazu bietet auch in diesem Jahr wieder das „Greifswalder Ryck-Symposium“. Es sind noch Plätze frei.

Den nützlichen Teil bildet am 2. und 3. September wieder ein breit gefächertes Programm für MTRA mit spannenden und interessanten Vorträgen. Zudem wird es diesmal auch Hands-On-Workshops geben.

Zum angenehmen Teil zählt auf jeden Fall wieder ein Segeltörn, der inzwischen beim Greifswalder Ryck-Symposium schon zur Tradition gehört. Die „Weiße Düne“ ist bereit für die Teilnehmer. Wem das aber nicht genug Vergnügen ist, dem seien ein paar
Tage Urlaub in Greifswald und Umgebung empfohlen.

$\mathrm{Zu}$ den Sehenswürdigkeiten zählen u.a. das Pommersche Landesmuseum, die Klosterruine in Eldena oder der Dom St. Nikolai. Wer reizvolle Landschaften und Natur pur sehen möchte, der findet alles reichlich auf den nahe gelegenen Inseln Rügen, Usedom und Fischland Darß. Und Wasser gibt es natürlich überall, ob bei einer Paddeltour auf dem Ryck, einer Angeltour auf dem Greifswalder Bodden oder beim Baden in der Ostsee. Auch mit dem Fahrrad lässt sich die Region wunderbar erfahren. Viele weitere Informationen und Anregungen bieten die Internetseiten der Touristikbüros.

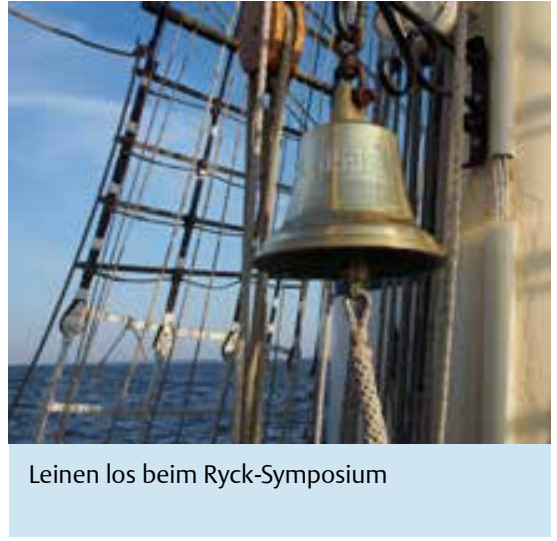

Also, ein Vermerk im Terminkalender: 2./3. September „Ryck-Symposium“ in Greifswald lohnt sich auf jeden Fall.

Das komplette Programm und die Anmeldung finden Sie auf www.vmtb.de > Veranstaltungen 